\title{
HIV-Therapie
}

\section{Ärzte können aus dem Vollen schöpfen}

Mehr als 25 antiretrovirale Wirkstoffe und mehrere Fixkombinationen sorgen für den Erfolg der modernen Behandlung von HIV-positiven Menschen. Deren Lebenserwartung hat sich drastisch erhöht.

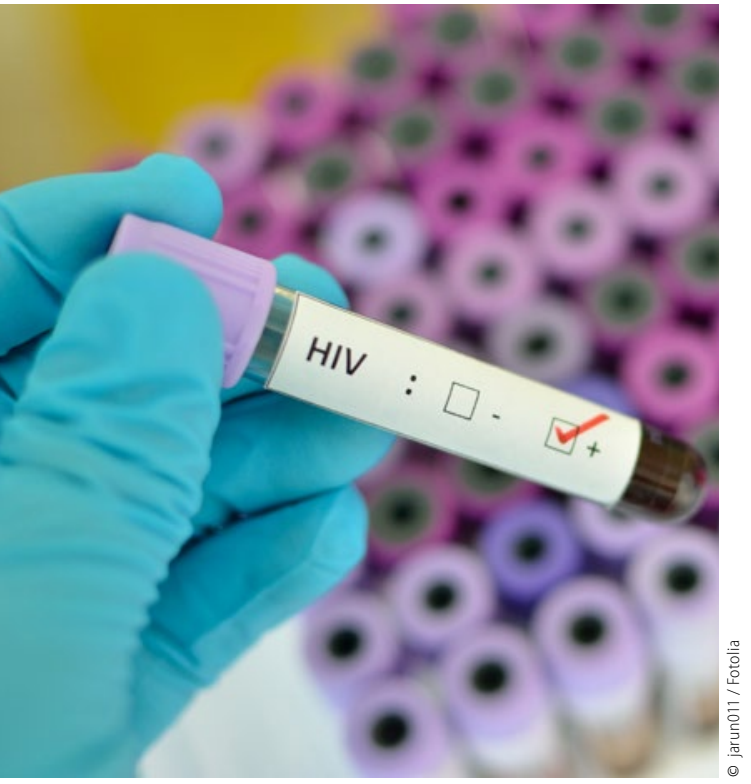

Positiver HIV-Test: Vor Therapiebeginn wird ein HIV-Genotyp-Resistenztest empfohlen.

Derzeit leben in Deutschland etwa 85.000 Menschen, die mit dem AIDS-Erreger HIV infiziert sind. Die medikamentöse Therapie dieser Infizierten mit antiretroviralen Medikamenten ist im Vergleich zum Beginn der Pandemie Anfang der 1980er-Jahre ausgesprochen effektiv geworden. Mit dieser Behandlung haben HIV-Infizierte inzwischen eine fast normale Lebenserwartung.

Heute stehen den Therapeuten mehr als 25 Einzelsubstanzen aus fünf verschiedenen Wirkstoffgruppen zur Verfügung: NRTI (nukleosidische ReverseTranskriptase-Inhibitoren), NNRTI (Nicht-NRTI), Proteasehemmer, EntryInhibitoren und Integrasehemmer sowie zwei Booster-Substanzen, also Wirkverstärker. Inzwischen gibt es mehrere Fixkombinationen, die bis zu vier Substan- zen in einer Tablette vereinen. 18 Monopräparate liegen auch in Form kindgerechter Darreichungsformen vor.

\section{Genotyp-Resistenztest vor ART}

Die antiretrovirale Behandlung (ART) wird allen chronisch mit dem AIDS-Erreger infizierten Erwachsenen empfohlen, wie es in der aktuellen Leitlinie der europäischen AIDS-Gesellschaft EACS (European AIDS Clinical Society) vom Januar 2017 heißt, und zwar unabhängig davon, wie hoch die Zahl der CD4-positiven T-Helferzellen ist. Je niedriger jedoch die Zellzahl sei, umso dringender sei ein frühzeitiger Therapiebeginn. Vor Beginn der antiretroviralen Behandlung wird ein HIV-Genotyp-Resistenztest empfohlen, am besten zum Zeitpunkt der Diagnose, spätestens beim Therapiestart. Sollte es erforderlich sein, die ART noch vor dem Vorliegen des Genotyptests zu beginnen, empfiehlt die EACS, mit einem Präparat zu beginnen, bei dem in der Ersttherapie kaum mit einer Resistenz zu rechnen ist, etwa mit einem geboosterten Proteasehemmer oder Dolutegravir.

Für die initiale Therapie werden stets Kombinationen mehrerer Präparate empfohlen. Drei Optionen fürs Kombinieren schlägt die Gesellschaft in ihrer Leitlinie vor: 2 NRTIs plus 1 Integrasehemmer, 2 NRTIs plus 1 NNRTI oder 2 NRTIs plus einen geboosterten Proteasehemmer. Ist eine Behandlung mit den initial ausgewählten Kombinationen nicht möglich, empfiehlt die Gesellschaft, auf andere Substanzen der jeweils selben Wirkstoffgruppe auszuweichen. Ein Versagen der ART liegt der Leitlinie zufolge vor, wenn die HIV-Viruslast innerhalb von sechs Monaten nach Therapiebeginn über 50 HIV-RNA-Kopien/ml liegt.

\section{Empfehlungen für sofortige ART}

Für die primäre HIV-Infektion empfiehlt die Leitlinie in bestimmten Fällen einen sofortigen Therapiebeginn. Dabei ist eine primäre HIV-Infektion anzunehmen, wenn Personen innerhalb der vergangenen sechs Monate einem erhöhten Expositionsrisiko ausgesetzt waren und zudem im Plasma das p24-Ag und/oder die HIVRNA nachweisbar ist und/oder sich eine Anti-HIV-Antikörper-Reaktivität entwickelt. Zwischen 23 und $92 \%$ der primär Infizierten haben klinische Symptome. Leitsymptome sind Lymphknotenschwellung, Fieber, ein makulopapulöses Exanthem und Myalgien. Zu einer sofortigen ART sollte der Leitlinie zufolge bei einer akuten Infektion, bei ausgeprägten Symptomen, Symptomen einer neurologischen Erkrankung und bei über 50-Jährigen sowie bei

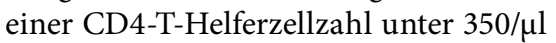
geraten werden.

\section{Viele HI-Viren neutralisieren}

Große Hoffnungen setzen HIV-Therapeuten auf die Anwendung breit neutralisierender Antikörper nicht nur in der Vakzineentwicklung, sondern auch für die Therapie. Diese Antikörper sind in der Lage, viele unterschiedliche HI-Viren zu neutralisieren. In einer aktuellen Studie, an der auch deutsche HIV-Therapeuten von der Universitätsklinik Köln teilgenommen haben, sprachen 11 von 13 virämischen HIVInfizierten rasch auf die Therapie mit dem Antikörper 10-1074 an, der 2012 im Blut eines HIV-Infizierten entdeckt und daraus isoliert worden war: Innerhalb von durchschnittlich zehn Tagen nach der einmaligen Infusion des Antikörpers sank die Zahl der HIV-RNA-Kopien am stärksten [1]. Eine signifikante Reduktion der HIViren im Blut wurde vom dritten bis zum 27. Tag nach der Infusion dokumentiert. Geplant ist, breit neutralisierende Antikörper zur Unterstützung einer ART zu verabreichen.

Peter Leiner 